This paper has been published at the Journal of Cleaner Production, 179, 210-216, 2018

https://doi.org/10.1016/j.jclepro.2018.01.113

\title{
Assessing vegetation response to multi-time-scale drought across Inner Mongolia Plateau, China
}

Chunlan $\mathrm{Li}^{1,2,3}$, Walter Leal Filho ${ }^{3 *}$, Jie Yin ${ }^{1,2}$, Richa Hu${ }^{4}$, Jun Wang ${ }^{1,2}$, Chengshu Yang ${ }^{1,2}$, Shan Yin ${ }^{4,5}$, Yuhai Bao ${ }^{4,5}$, Desalegn Yayeh Ayal ${ }^{6}$

1School of Geographical Sciences East China Normal University, Shanghai 200241, China

2 Key Laboratory of Geographic Information Science of Ministry of Education, East China Normal

University, Shanghai 200241, China;

3 Hamburg University of Applied Sciences, Research and Transfer Centre "Sustainable Development

and Climate Change Management" and School of Science and Environment, Manchester Metropolitan

University, Chester Road, Manchester M1 5GD, UK

4 College of Geographical Sciences, Inner Mongolia Normal University, Huhhot 010022, China

5Key Laboratory of Remote Sensing and Geographic Information System, Inner Mongolia, Huhhot

010022, China

6 Addis Ababa University, College of Development Studies, Centre for Food Security Studies, Addis

Ababa, 150129, Ethiopia

E-mail addresses of all authors:

Chunlan Li: 15598022233@163.com; Walter Leal Filho: walter.leal2@haw-hamburg.de

Richa Hu: huricha@imnu.edu.cn; Jun Wang: jwang@geo.ecnu.edu.cn;

Chengshu Yang: chengshu.y@qq.com; Shan Yin: yinshan@imnu.edu.cn;

Yuhai Bao: baiyuhai@imnu.edu.cn; Desalegn Yayeh AYAL: desalula@gmail.com

* Corresponding author: Walter Leal Filho, School of Science and the Environment, Manchester

Metropolitan University, UK \& Hamburg University of Applied Sciences, Research and Transfer Centre

"Sustainable Development and Climate Change Management", Ulmenliet 20, D-21033 Hamburg, Germany

\begin{abstract}
This study assessed the impacts of climate change in IMP by investigating vegetation responses drought in multiple timescales. Methods used included the Normalized Difference Vegetation Index (NDVI) and Standardized Precipitation Evapotranspiration Index (SPEI), by annual maximum Pearson correlation (Rmax) and the corresponding month (Rmonth) of drought. Results showed that: (1) It is necessary to zone IMP when analyzing the vegetation responses to drought. (2) Rmax is significantly positive correlation in IMP, indicating that vegetation was largely influenced by drought; the most seriously affected areas are in the north-eastern part of typical steppe, south-western parts of steppe desert and southern part of desert steppe, while light seriously are distributed in the south-eastern of typical steppe and forest steppe. (3) Vegetation in typical steppe, steppe desert and desert steppe are sensitive to shorter time-scales of droughts, while in the forest, forest steppe and sand desert, vegetation shows a close relationship with the longer drought time-
\end{abstract}


scales. (4) The effects of drought related climate extremes can also contribute to Rmax and Rmonth between SPEI and NDVI. Vegetation in forest and sand desert areas, have lower sensitivity to drought under the effect of climate extremes. Adaptation measures, such as building drought resilience vegetation types, applying biochar and monitoring and forecasting drought, must be timely and effectively initiated, especially, in the typical steppe, steppe desert and desert steppe in IMP since vegetation in these four areas is affected seriously, once drought occur. The results from this study may provide useful information about appropriate adaptation and mitigation strategies against the inverse effects of drought on vegetation, and even alleviate the losses caused by drought.

\section{Highlights}

1. Vegetation in forest, forest steppe and sand desert have sensitivity to drought in longer time-scales

2. Anomalies in precipitations are seen in the Inner Mongolia Plateau in China

3. Inner Mongolia Plateau (IMP) in China is under the serious drought risks and measures to tackle it are needed

4. Drought-related climate extremes negatively affect vegetation

Keywords: Normalized Difference Vegetation Index (NDVI), Standardized Precipitation Evapotranspiration Index (SPEI), Steppe, Climate extremes, Inner Mongolia Plateau (IMP)

1 Introduction

Climate change is known to impact on society and ecosystems in a variety of ways (Leal Filho 2015). One of the obvious ways is drought, which is period of below-average precipitation in a given region, resulting in prolonged shortages in the water supply, such as continuous no rain days or the anomaly of the precipitation (Zhang and Li., 2007). In such circumstances, supply cannot satisfy the existing demand (Vicente-Serrano et al., 2013). According to statistics from Emergency Events Database (www.em-dat.net), throughout the world, droughts account for $5 \%$ of the natural disasters, but losses from droughts have caused up to $30 \%$ of losses from all disasters, ranking droughts the first among all the natural hazards. With global warming, it is now generally agreed that the global hydrological cycle would intensify and that the extremes of drought would become more common (Mishra et al., 2009) and become even more serious, especially since the late 1990s (Yu et al., 2014). Drought has the characteristics of high frequency, long duration and wide influence, and has far-reaching impact on agricultural production, ecological environment and social and economic development, especially in agricultural production on (Donald, 1994). Compared with other land use types, grassland is most sensitive to drought (Zhang et al., 2017). Drought with increasing frequency has extremely important effects on animal husbandry and pasturing (Natsgadorj, 2003) and can result in huge losses. According to Xinhua news (http://news.xinhuanet.com/english/2017-07/14/c 136444349.htm), in July 2017, only in Inner Mongolia Autonomous Region of People's Republic of China, there are 2.7 million hectares of crops and 34.3 million hectares of grassland being severely affected by drought, resulting in the 
direct economic loss was up to 5 billion CNY. It is of great practical significance to explore the effect of drought on vegetation growth and to drought impact assessment and agricultural production. Analysis how grassland vegetation responds to drought is the key point to alleviate the losses caused by drought. Thus, grassland vegetation response to drought is a crucial scientific issue in the domain of climate research.

Inner Mongolia Plateau (IMP) is the largest cross-long distance between the provinces in People's Republic of China with a span of $2400 \mathrm{~km}$, and its climate differences from south to north are obvious, which results in its vegetation differences. Vegetation have different demands on water in different growing periods; therefore, the drought has different effects on grassland vegetation (Liu et al., 2012). That indicates different vegetation has different stability and resilience to drought resistance ( Zhang et al., 2017), thus, different grassland types have different responses to the drought during the growing periods. Additionally, the spatial variability was covered by using the limitation mean of overall vegetation response to drought in IMP. To reduce influences of these biases, zoning of vegetation needs to be done when analysis its response to drought. What's more, drought in multi-time-scale needed to be taken into consideration (McKee et al., 1993). Hence, when analysis vegetation response to drought, different vegetation types need to be studied separately and their responses to drought in different time-scale also require consideration. The effects of drought are complex and difficult to grasp and predict, and it is necessary to use several well-established drought indices to qualitatively and quantitatively measure the drought. After analysis, Standardized Precipitation Evapotranspiration Index (SPEI) is a widely used method to evaluate drought index, which is a site-specific drought indicator quantifying deviations from the average water balance (precipitation minus potential evapotranspiration) and has various time-scales (Vicente-Serrano et al., 2010). And we used Normalized Difference Vegetation Index (NDVI) to calculate vegetation coverage, which a good indicator of vegetation activity and has been widely used to estimate dynamic of vegetation (Guo et al., 2014). Vicente-Serrano et al. (2013) have investigated vegetation response to drought by analysis the relationship between SPEI and NDVI.

IMP is a typical agriculture-gazing transitional zone with 8.7 million hectares of grassland in the Inner Mongolia Plateau, accounting for $76.5 \%$ of the total area, and ranking this area as the first of five major grasslands in People's Republic of China. Agriculture and animal husbandry is the main economic basis of Inner Mongolia Plateau, which contribute about $26 \%$ of region's gross domestic product, while $80 \%$ of the output value of agriculture and comes from animal husbandry. While animal husbandry in Inner Mongolia is affected by the drought (Li et al., 2007) and large agricultural and economic losses were caused by drought, which further harmed social life (Yuan et al., 2013). Investigation of vegetation response to different timescales droughts across IMP will give us insight into the impacts of droughts on grasslands and help to make plans and management to reduce agricultural and economic loss. Many investigations (e.g. Wang et al., 2017) have been focused on vegetation responses on climate change or the occurrence and intensity of drought. In addition, most research is focused on local elements, ignoring the spatial heterogeneity (Wang et al., 2017). Nevertheless, the response mechanism of different grassland vegetation to drought is still far from complete.

Based on the points above, responses of different steppe vegetation to drought in different time-scales in IMP need to be the subject of considerable attention. The objectives of this study were: (1) to investigate 
relations and sensitivities of vegetation in different grasslands responses to drought in different time-scales in IMP; (2) to understand impacts of drought-related climate extremes on vegetation responses to droughts. The following section is an introduction of the study area in IMP; section 3 gives an overview of data and methods applied in this study; section 4 and section 5 present the results and discussions, respectively; The conclusions and some suggestions for further researches are given in section 6.

\section{Study area}

Inner Mongolia Plateau (IMP) is selected as study area in this paper, which extends over more than $6^{\circ}$ of latitude (between $37^{\circ} 24^{\prime} \mathrm{N}$ and $53^{\circ} 23^{\prime} \mathrm{N}$ ) and $19^{\circ}$ on longitude (between $97^{\circ} 12^{\prime} \mathrm{E}$ and $126^{\circ} 04^{\prime} \mathrm{E}$ ) (Fig. 1), with a total area of about 1.18 million $\mathrm{km}^{2}$. Due to its elongated shape elevations ranging from $82 \mathrm{~m}$ to 3430 m (above sea level) (Wang et al., 2013). Greater Hinggan Mountains are located on the northeast and Ho-lan Mountains is on the west. Yin Mountains run across the central portion of this province. There are a wide variety of regional climates in IMP and most parts of them are arid, semi-arid or semi-humid from west to east, except for the relatively humid Greater Hinggan Mountains region (Liu et al., 2016). Meanwhile, precipitation gradually decreases from east to west with the annul change between 50 to $450 \mathrm{~mm}$. The average annual temperature is approximately -1 to $10^{\circ} \mathrm{C}$, because of this complex topography and distance from the oceans, vast grasslands are distributed in the east of the region and deserts are mainly widespread in the west. IMP is one of the most important bases for agriculture and livestock production, characterized by a combination of rangeland-based livestock systems and mixed farming systems ( $\mathrm{Mu}$ et al, 2013), which is very sensitive and vulnerable to drought.

In this study, IMP is geographically divided into six sub-regions based on previous studies ( $\mathrm{Li}, 1990)$, including desert steppe, forest, forest steppe, sand desert, steppe desert, and typical steppe, the location are depicted in Fig. 1. 


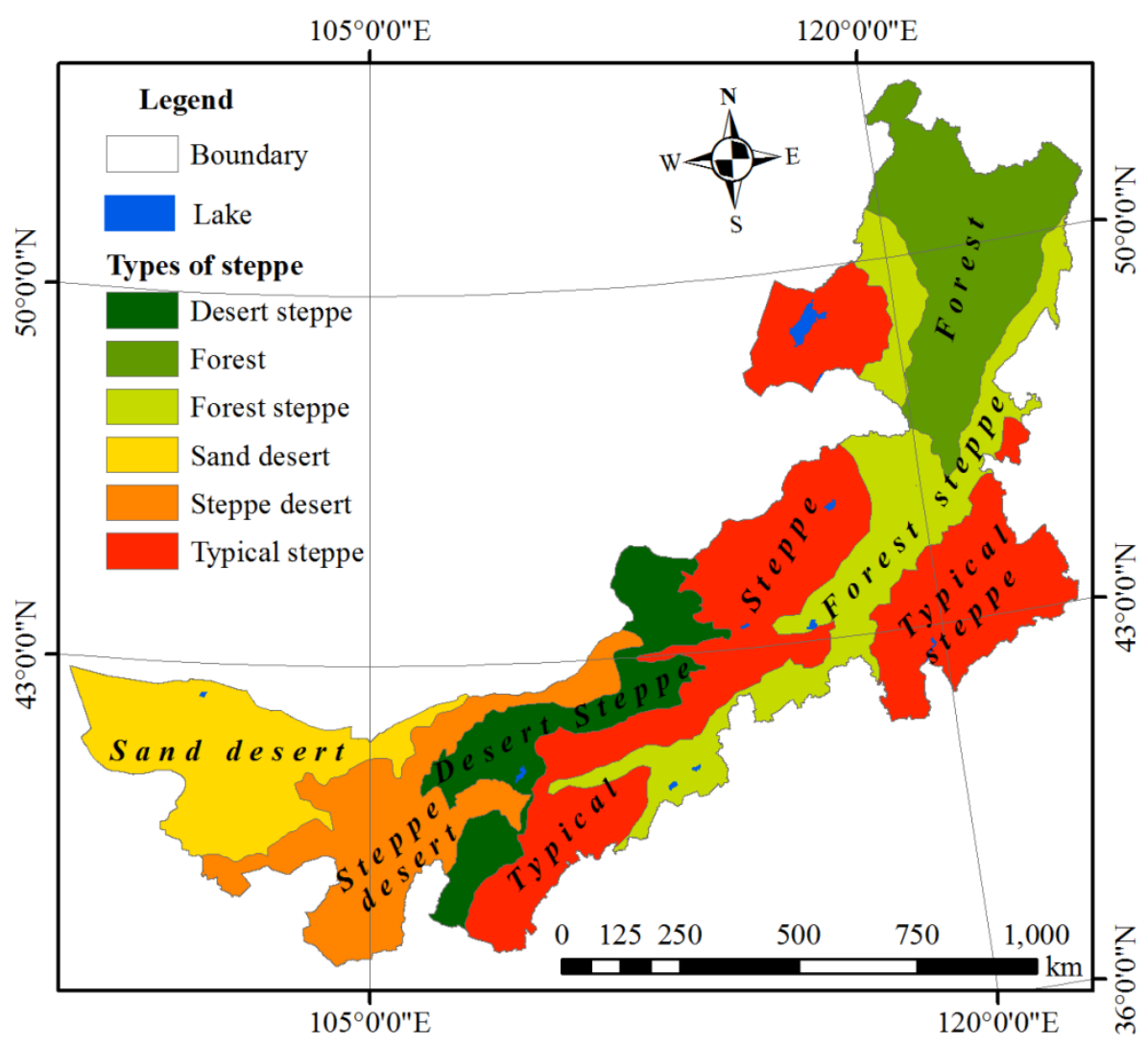

Fig. 1. Location of different steppes in IMP

\section{Data and Method}

\subsection{Data}

\subsubsection{Time series of monthly normalized difference vegetation index (DNVI)}

The GIMMS NDVI3g dataset (https://nex.nasa.gov/nex/projects/1349/) were used in this study since it is well known as high quality (Gao et al., 2017) and also widely used to identifying longest time period of trends in vegetation activity (Xu et al. 2014). These dataset is at a spatial resolution of $8 \mathrm{~km}$ and a 15-day temporal interval for the period from January 1982 to December 2015. After validation and correction (Tucker et al., 2006), the monthly NDVI had been generated from the processed biweekly NDVI composites which can minimize the effects of cloud contamination (Holben et al., 1986).

\subsubsection{Meteorological data}

To match the span of NDVI, monthly mean temperature and precipitation were collected from 1980 to 2015 for drought index, while daily maximum and minimum temperature and precipitation data were from 1982 to 2015 for extreme climate indices. All these data were collected from China Meteorological Data Sharing Service System (CMDC) including 43 meteorological stations in IMP. This paper adopts the Kriging Interpolation Method based on the NDVI spatial resolution to interpolate the drought index and extreme 
climate indices data, as this method has been widely used in geology, to process spatial interpolation of meteorological data (Liu et al., 2012).

\subsection{Method}

\subsubsection{Standardized Precipitation Index (SPEI)}

Drought index can be used as an indicator of the extent of drought and is also a numerical expression of drought description. Precise and commonly used drought index is very important. Analysis has found that sc-PDSI and SPEI can identify an increase in drought severity associated with higher water demand as a result of evapotranspiration under the global warming (Vicente-Serrano et al., 2010). Drought in multi-timescale has been considered in this study. SPI and SPEI are often used by scholars to study the extreme climate phenomena such as drought caused by the change of climatic factors, which can better reflect the intensity and duration of drought and reflect the changes in different time scales and regions (Zhao et al., 2017). Based on this analysis, SPEI is the selected drought indicator in this study, which not only can identify evapotranspiration, but also within multi-time-scales. And its details description is put forwards by VicenteSerrano et al (2010).

\subsubsection{Correlation analyses}

Correlation between sets of data is a measure on how well they are related, and in stats Pearson correlation is the most used measure of correlation. (http://www.statisticshowto.com/what-is-the-pearsoncorrelation-coefficient/). Additionally, the relationship between vegetation and SPEI should be analyzed in each month separately. Based on this, Pearson correlation analyses were conducted for the NDVI (12 months) vs. 1-, 2-, . ., and 24-month SPEI based on the pixel-by-pixel in this study. Finally, correlation coefficients and their corresponding p-values were obtained. Due to the study period length of 34 years, the values of 0.30 and 0.4 are corresponding to $5 \%$ and $1 \%$ significant levels of their corresponding correlation coefficients.

Because there are 12 data sets of NDVI and 24 data sets of SPEI at each pixel, there were $288(12 * 24)$ correlation coefficients for each pixel. To eliminate the influence of phenology on correlation analysis results, the monthly correlations were summarized annually. For this purpose, only the annual maximum correlation coefficient Rmax was left (Vicente-Serrano et al., 2013). The corresponding SPEI time-scale where Rmonth was obtained is considered as the time-scale of vegetation responding to drought. The subsequent analysis was done with focus mainly on Rmax and Rmonth of vegetation response to drought.

\section{Results and discussions}

\subsection{Relations between vegetation in different steppes to drought in different time-scales}

Drought disaster is one of the most important meteorological disaster affecting the production of animal husbandry in grassland pastoral in IMP (Li et al., 2010). While vegetation change in different steppes, IMP is one of the most important bases for their agriculture and livestock production. Therefore, how drought affects vegetation is urgent when considering the influence of drought on vegetation. Analysis has been found that the Rmax between SPEI and NDVI is an indicator which can describe the impact of drought on vegetation 
and Rmonth corresponds to illustrate the sensitivity of vegetation to drought (Vicente-Serrano et al., 2013). The longer time-scale of related Rmonth between SPEI and NDVI, the stronger resistance or strong resilience of vegetation to drought, which can indicate insensitivity of vegetation response to drought (Zhang et al., 2017). Fig. 2 illustrates that all steppes in IMP are dominated by significantly positive correlations between NDVI and SPEI, which implies that most vegetation in IMP are largely affected by drought. Fig. 2 also implies that the extent of vegetation affected by drought decreases from north-west to south-east and the densest areas are in the typical steppe and desert steppe. The weaker NDVI vs. SPEI correlations were detected within south-western part of IMP, particularly in south-western and south-eastern parts of typical steppe, south-western parts of steppe desert and southern part of desert steppe. Weak correlations between NDVI and SPEI were also identified in the middle parts of forest and forest steppe. Forest and forest steppe in IMP is more humid than the other steppes due to the Great Khingan Mountain, but some parts of vegetation in these two areas also showed a close relation to drought.

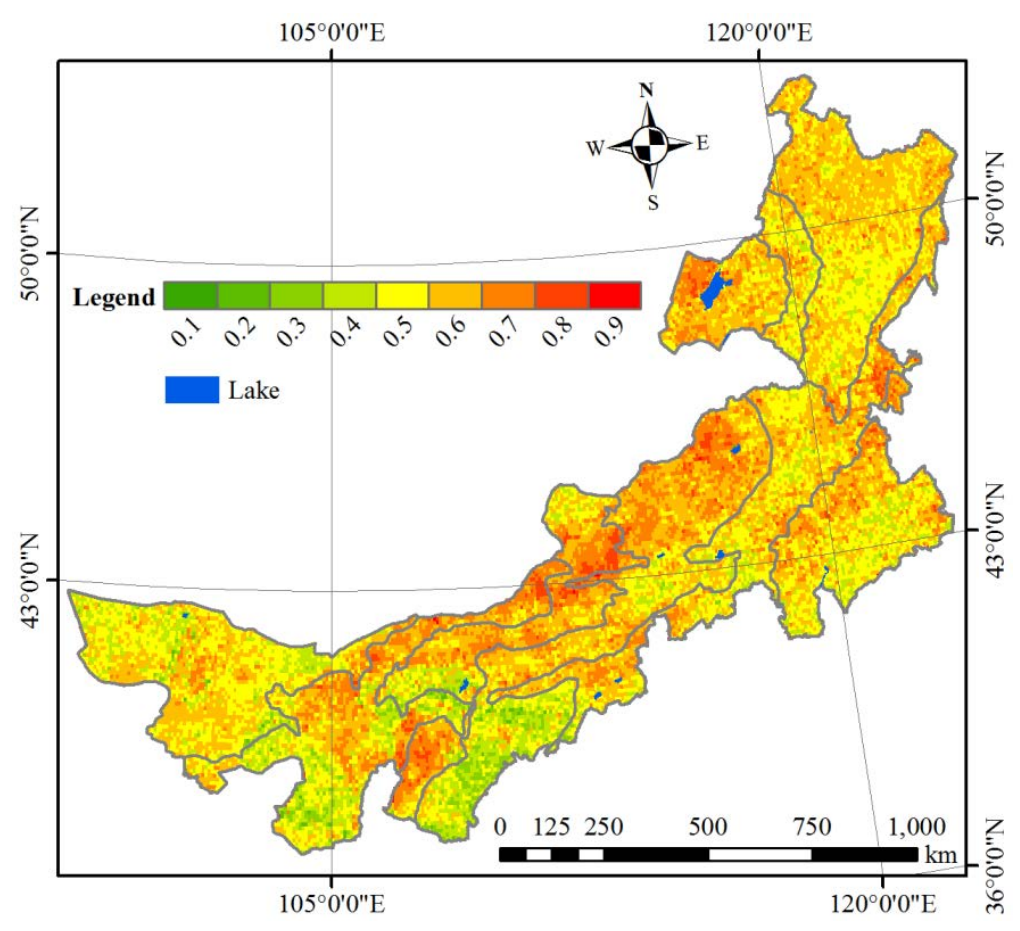

Fig. 2. Spatial distribution of annual maximum correlation coefficients between SPEI and NDVI during the period of 1982-2015, independently of the month of the year and the SPEI time-scales. The values of 0.30 and 0.4 are corresponding to $5 \%$ and $1 \%$ significant levels of those correlation coefficients.

From analysis above, it can be concluded that the drought-resilience vegetation in IMP is increasing from north-west to south-east of IMP. A large area of higher drought-resilience vegetation is in the south-eastern part of typical steppe and forest steppe, while most parts of drought-vulnerable vegetation are in the northeastern part of typical steppe, south-western parts of steppe desert and southern part of desert steppe.

\subsection{Sensitivity of vegetation in different steppes to drought in different time-scales}


Under the influence of global warming, the growth of grassland vegetation was significantly affected by extreme climate change in recently years (Zhao et al., 2017), ultimately changing the function of grassland ecosystem (Philip et al., 2008) and even bringing lots of losses and damages (Sarah et al., 2015), especially being caused by drought (Li et al., 2012). Drought is an extreme climate-related phenomenon of complex nature, becomes difficult to readily detect and evaluate its onset and evolution (Spinoni et al., 2015). Previous researches mainly focused on the relation between vegetation and drought, with few studies considering drought time-scales (Liberato et al., 2017) or vegetation changes in close relation with different time-scales of droughts, but they are all at regional and global scales (Vicente-Serrano et al., 2013). However, different time-scales of drought at plateau area should be considered with the aim to plenty understand the possible causes behind vegetation response to drought. Because IMP is long and narrow with a span of $2400 \mathrm{~km}$ from west to east with strip of land sloping from northeast to southwest, and its climate differences from south to north are obvious which results in vegetation types in IMP. Moreover, IMP is People's Republic of China's ecological security barrier, but also the source of sands. It is easy to understand that why it is important to analyze vegetation in IMP responses to drought in different time-scales. It can be seen from Fig. 3 that NDVI is sensitive to the timescale of 4-9 months of SPEI in the middle parts of IMP, where located in the typical steppe, steppe desert and desert steppe, and grow Stipa capillata Linn, Artemisia afrigida, Filifolium sibiricum, respectively. Some types of vegetation in these three steppe areas were annual plants (Chen et al., 2006) and the growth periods of this vegetation are 5-5.5 months (Gao et al., 2013). Some man-made artificial vegetation is planted in the typical steppe and steppe desert areas, and in the desert steppe area, there are irrigated and dry land vegetation. Nevertheless, grassland vegetation was protected and restored by the ways of encirclement grazing, spring grazing, zoning grazing due to the strategy of "encirclement and transfer" (Bu, 2005). All these measures can prolong the lifetime of vegetation than before. Therefore, the short timescale of NDVI responses to drought is longer than the previous research (Zhang et al., 2017), due to the human interference on vegetation.

Higher sensitivity of vegetation to longer time-scales of droughts, 12-24 months, was observed in the west and east parts of IMP, where located in forest, forest steppe and sand desert, which can imply the tardy response of vegetation to the influence of droughts in these kinds of steppes. Normally, water is the main factor limiting of vegetation in the arid area with low precipitation, plus excessive temperature has largely accelerated the evaporation, resulting in the water deficit in soil and atmosphere which eventually inhibit vegetation growth. However, the possible causes behind these tardy vegetation responses in the abovementioned steppes are complicated, and they are different from with others. Spatially, NDVI in sand desert dominated area is sensitive to SPEI at the timescale of 18-22 months, where the vegetation is mainly about drought - resistant vegetation, such as Mongolian calligonum, Haloxylon and Caragana microphylla. In the forest, the precipitation is enough for vegetation growth, the main vegetation are about Deciduous broadleaf forest, White birch and Mongolian oak forest, which are all high resistant to drought. Nevertheless, in the forest steppe area, there are some man-made Artificial vegetation and Perennial shrubs and forbs, and these kinds of vegetation are easy to adapt to the drought due to their higher drought resistance. Thus, vegetation, dominated in these three steppe areas, are higher sensitivity of longer time-scales of SPEI. 


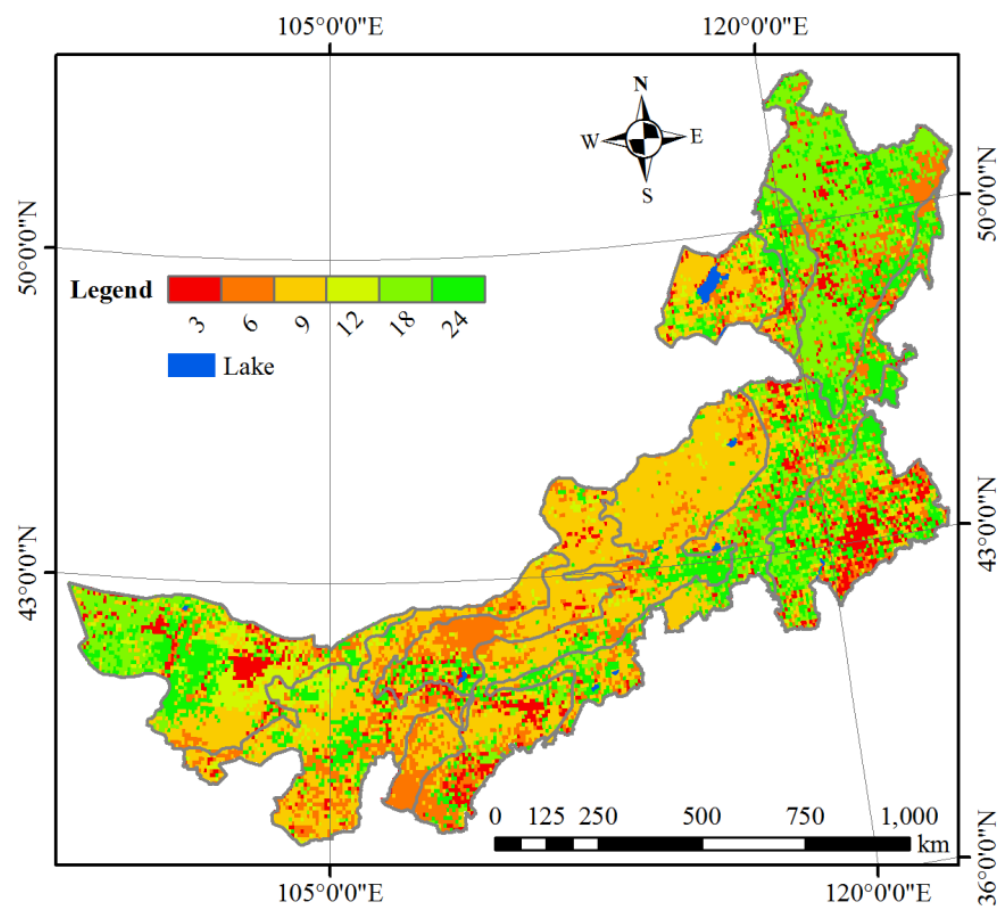

Fig. 3. Spatial distribution of corresponding time-scales where the maximum correlation coefficients were found in Fig.2

From Fig. 3. the spatial analysis of NDVI responses to time-scales of SPEI, it can be easily concluded that vegetation in typical steppe, steppe desert and desert steppe are sensitive to shorter time-scales of droughts, while in the forest, forest steppe and sand desert, vegetation shows a close relationship with the longer drought time-scales. The causes of these results vary in different steppes. When forecast drought and its effects, its time-scales should be fully considered as well.

\subsection{Extreme climate factors behind vegetation response to drought time-scales}

It is clear noticed that shortage of water resources is the limitation factor for vegetation growth in the arid area. At the same time there are some other climate extremes along with drought. When analyzing the vegetation responses to drought, the other climate extremes cannot be ignored. Previous studies also attempted to investigate the factors of vegetation responses to drought time-scales (Vicente-Serrano et al., 2013), but they only considered the mean status of climate change (Zhang et al., 2017). Hence, more climate extremes factors should be taken into consideration since one extreme event is always associated with other extremes. It is reasonable assumption to discuss climate extremes along with drought can influence on the result of vegetation response to drought.

Defining ecological drought for the 21st century indicated that hotter temperatures is one of main characteristics of drought (Crausbay et al., 2017). Based on this definition, eight extreme indices related drought were chosen in this study, including warm spell duration indicator (WSDI), monthly maximum value of daily minimum temperature (TNx), monthly maximum value of daily maximum temperature (TXx), tropical nights (TR20), summer days (SU25), warm days (Tx90p), warm nights (Tn90p) and consecutive dry days (CDD). Their detail principles were described by Wang (2008). After quality control assessments 
by software RClimDex1.1 and homogenized test by software RHtest V4, eight extreme indices were calculated and then interpolated by Kring method with the same spatial resolution of NDVI.

In order to figure out how climate extremes influenced vegetation response to drought, the relation between extreme climate indices and Rmax and Rmonth needed to be calculated, respectively. Pixel data of them was obtained to improve the accuracy of results. The relations between extreme climate indices and Rmax and Rmonth were shown in Table 1. From Table 1, it is easy to find that the extreme climate indices which influence Rmax, and Rmax are different between IMP and 6 sub-regions, which greatly emphasizes the necessity of zoning IMP from a quantitative point of view. Normally, to some extent, the higher increase of extreme temperature or hot index, the higher influence or sensitive of vegetation response to drought since hot environment accelerate evaporation, and eventually vegetation becomes easily influenced by drought. It is interesting to find complications within IMP, especially in forest and sand desert, the results were the contrary. In the forest area where vegetation has sufficient water for growth, and the water may be not the main limiting factor (Zhang et al., 2013), but temperature is the main causal factor, and physiological and biochemical reactions of vegetation there would increase with the extreme temperature increase. However, vegetation in the sand steppe area are drought-tolerant and perennially affected by water deficit, hence surviving vegetation there have adapted well to the arid growth environment by self-regulation. For example, plants in the sand desert area can endure the intense heat of desert by changing their growth leaves or using longer roots to store water (Brunner et al., 2015) (http://factsanddetails.com/world/cat52/sub331/item1178.html). Even though some extreme temperatures often occur, vegetation in sand desert area can be quickly restored and adapted to extreme environments. Therefore, vegetation, in forest and sand desert area, have been affected by drought apparently under the effect of climate extremes.

Analysis found that Rmonth can express the degree of sensitivity of vegetation response to drought multi-time-scales, and this degree of sensitivity varies in different sub-regions (Zhang et al., 2017). It means the higher Rmonth, the lower sensitive to drought accompanied by the temperature extreme increasing. It can be seen from Table 1 that, WSDI, Tn90p and CDD are the main extremes indices which can affect sensitivity of vegetation response to drought time-scales. If a long period of warm conditions (WSDI), exceeds a certain threshold, vegetation growth will be largely affected and damaged, and could even die from chronic hunger (Zhang et al., 2005). Under long term of warm nights (Tn90p), the increasing respiration of vegetation may restrict vegetation growth, and ultimately lead to vegetation which is more sensitive to drought. Consecutive dry days (CDD) indicates there is a low precipitation in the living surrounding area, which can directly influence plants growth.

Table 1 Relation between extreme climate indices and maximum correlation coefficient and corresponding month

\begin{tabular}{|l|c|c|c|c|c|c|c|c|}
\hline & WSDI & TNx & TXx & TR20 & SU25 & Tx90p & Tn90p & CDD \\
\hline Rmax_IMP & $-0.108^{* *}$ & $-0.198^{* *}$ & $-0.078^{* *}$ & $-0.174^{* *}$ & $-0.202^{* *}$ & $0.061^{* *}$ & $-0.139^{* *}$ & $-0.106^{* *}$ \\
\hline
\end{tabular}




\begin{tabular}{|c|c|c|c|c|c|c|c|c|}
\hline Rmax_Desert_steppe & $-0.152^{* *}$ & $-0.166^{* *}$ & $-0.193^{* *}$ & $-0.193^{* *}$ & $-0.195^{* *}$ & $0.104^{* *}$ & $-0.154^{* *}$ & $-0.219 * *$ \\
\hline Rmax_Forest & $0.116^{* *}$ & $-0.066^{* *}$ & 0.011 & $0.104^{* *}$ & $-0.046^{*}$ & $0.186 * *$ & $-0.068 * *$ & $-0.155^{* *}$ \\
\hline Rmax_Forest_steppe & -0.023 & -0.025 & $-0.066^{* *}$ & $0.102^{* *}$ & $0.050^{* *}$ & $-0.245^{* *}$ & $0.087^{* *}$ & $0.170^{* *}$ \\
\hline Rmax_Sand_desert & $0.126^{* *}$ & $0.076^{* *}$ & $0.062^{* *}$ & -0.017 & $-0.068^{* *}$ & $-0.188^{* *}$ & $0.069^{* *}$ & $0.074^{* *}$ \\
\hline Rmax_Steppe_desert & $-0.260 * *$ & $-0.353 * *$ & $-0.293 * *$ & $-0.376^{* *}$ & $-0.334 * *$ & $-0.048 *$ & $-0.055^{* *}$ & $-0.323 * *$ \\
\hline Rmax_Typical_steppe & $-0.193 * *$ & $-0.104^{* *}$ & $0.285^{* *}$ & $-0.136^{* *}$ & $-0.324 * *$ & $0.161^{* *}$ & $-0.310^{* *}$ & $-0.345 * *$ \\
\hline Rmonth_IMP & $-0.162^{* *}$ & $0.021^{* *}$ & $0.176^{* *}$ & 0.012 & $-0.038 * *$ & $-0.219 * *$ & $-0.159 * *$ & -0.012 \\
\hline Rmonth_Desert_steppe & $0.083^{* *}$ & $0.108^{* *}$ & $0.076^{* *}$ & $0.168^{* *}$ & $0.141^{* *}$ & -0.025 & $0.055^{*}$ & $0.152 * *$ \\
\hline Rmonth_Forest & $-0.081 * *$ & $0.081^{* *}$ & $0.117 * *$ & 0.004 & $0.057 * *$ & $-0.053 * *$ & -0.033 & 0.015 \\
\hline Rmonth_Forest_steppe & $-0.088^{* *}$ & $0.035^{*}$ & $0.073^{* *}$ & $0.082^{* *}$ & $0.053^{* *}$ & $-0.145^{* *}$ & $-0.062^{* *}$ & $0.144^{* *}$ \\
\hline Rmonth_Sand_desert & 0.01 & 0.022 & 0.025 & $0.070^{* *}$ & $0.232^{* *}$ & $0.160^{* *}$ & $0.365^{* *}$ & $-0.396 * *$ \\
\hline Rmonth_Steppe_desert & 0.029 & $0.171^{* *}$ & $0.171^{* *}$ & $0.163^{* *}$ & $0.194 * *$ & $0.207 * *$ & $-0.250 * *$ & $-0.225^{* *}$ \\
\hline Rmonth_Typical_steppe & $-0.200 * *$ & $0.131 * *$ & $0.152^{* *}$ & $0.106^{* *}$ & $0.070 * *$ & $-0.285^{* *}$ & $-0.190 * *$ & $0.195^{* *}$ \\
\hline
\end{tabular}

Note: ${ }^{* *}$ and $*$ represent significant at $1 \%$ and $5 \%$ level, respectively.

Thus, from Table 1, it can be concluded that drought-related extremes temperature indices (e.g. WSDI, Tn90p and CDD) can affect sensitive of vegetation in different steppes response to drought time-scales, but not obviously in forest and sand desert area.

\section{Discussions}

It is inevitable that there are some possible errors and weaknesses in the final results (Yin et al., 2013). Firstly, zoning steppes entails potential uncertainties, which makes it hard to accurately deal with change process of steppe vegetation in different types. Some human disturbance to the environment, may also contribute to a result of uncertainty. For example, since 2000 grain for green project in IMP, forest area increased 2.638 million $\mathrm{hm}^{2}$ at the end of 2008, while desert area deceased by $3211 \mathrm{~km}^{2}$ and $934 \mathrm{~km}^{2}$, respectively, from 1999-2004 and 2004-2009 (Wu et al., 2009). Moreover, boundaries of steppes are also influenced by over-grazing, over-cultivation, coupled with rapid industrialization and urbanization process, mining on the grassland (Huang et al., 2009). What's more, there are some normal ecological successions (Liu et al., 2010). For example, ecosystem transformations from one state to another, e.g., forest to a shrub land (Jiang et al., 2013). Secondly, steppe vegetation are many annual plants, usually, this vegetation change is mainly due to their phenological characteristics rather than because of climate change (Chen et al., 2006), which would result in the uncertainty since these areas of change cannot be ignored Thirdly, uncertainties may arise from the existing but simple data with poor quality. Because most of them are secondary data with coarse time-resolution (e.g. monthly resolution in temperature and precipitation data, semi-monthly NDVI data) and coarse space-resolution (e.g. Kring interpolation based on the national-based meteorological station). Finally, all data used in this study only represent the past and present situation. Predictions for some 
variables and differences in the temporal character of the variables are not considered because the future drought and vegetation change processes are still largely uncertain in IMP. Despite the above shortcomings associated with each step, the analysis presented here is still considered useful as it provides a flexible and alternative method to aggregate existing knowledge on vegetation responses to drought and to help to implement measures of mitigation and planning. To obtain a more reliable conclusion, future works could be improved by addressing these uncertainties.

Adaptation measures, matched local conditions, must be timely and effectively initiated so as to minimize the drought risk. Typical steppe, steppe desert and desert steppe in IMP are the key areas needed to be comprehensively managed since they are sensitive to shorter time-scales of droughts. That indicate once drought occurs, vegetation in these three areas will be seriously affected. As an important part of the mitigation measures, drought resilience vegetation types adapted to IMP should be founded, particularly resistance of seeding, because it it the most vulnerable phase of the plant growth. Secondly, water retention ability of soil should be enhanced to reduce the losses of water evaporation and solution nutrients. Biochar is a good mitigation strategy (Kammann et al., 2011) to defense drought since it not only enables soil to store water and nutrient elements (Mulcahy et al.,_2013), but also provides microbial habitat and refugia for microbes whereby they are protected from grazing (Marousek et al., 2017). What's more, biochar can increase the life pan of vegetation and even increase in plant yields (Marousek et al., 2017) . Finally, as an important supplement, detailed local drought monitoring and forecasting must be prepared for all contingencies since failure of planting measures is always possible in such harsh and even high costing area. Moreover, because of the uncertainties in climate change, the above measures should be adapted in a flexible way.

\section{Conclusions}

This paper investigates vegetation in different steppes response to drought in multi-time-scales across IMP, through relations between NDVI and SPEI. Compared with previous studies, the novelty of this research lies in the following points: (1) This study sheds new light on different grasslands vegetation responses to drought in different time-scales; and (2) Impacts of more than one drought index were evaluated on vegetation responses to droughts. Drought-related extreme climate indices were also included in this current study. The results obtained are promising and indicate that vegetation in IMP is seriously affected by drought based on Rmax and Rmonth. The vegetation in forest and sand desert have lower sensitive to drought, while the rest four steppes (desert steppe, forest steppe, steppe desert, and typical steppe) in IMP have a higher sensitive to drought. These causes result not only from drought-resilience vegetation types, but also from the effect of drought related climate extremes. Timely and effective adaptation measures must be initiated to minimize the drought risk in the rest four steppes. Such detailed relations analysis of vegetation responses on drought may contribute to better understand the potential effect of drought on vegetation, and to help policy makers and other concerned stakeholders develop proper measures for vegetation protection. As an important part of the mitigation measures, the accuracy of drought prediction in advance is a key step, while building drought resilience vegetation types and applying biochar also very important. 
This study was jointly supported by National Natural Science Foundation of People's Republic of China (grant no. 41671095, 61631011and 51761135024) and the National Key Research and Development Program of People's Republic of China (No. 2017YFE0100700).

\section{References}

Brunner, I, Herzog C, Dawes MA, Arend M, Sperisen C (2015). How tree roots respond to drought.

Frontier Plant Science 6:547. Doi:10.3389/fpls.2015.00547

Bu HCL (2005). A Report on the Strategy of Enclosure Transfer. Inner Mongolia Social Sciences 137-141.

Crausbay S, Ramirez A, Carter S, Cross M, Hall K, Bathke D, Betancourt J, Colt S, Cravens A, Dalton M,

Dunham J, Hay L, Hayes M, McEvoy J, McNutt C, Moritz M, Nislow K, Raheem N, Sanford T (2017).

Defining ecological drought for the 21st century. American Meteorological Society. doi:10.1175/BAMS-D$16-0292.1$

Chen PQ, Yu SL, Zhang YN, Kang XL (2006). A review on plant heat stress physiology. Chinese Agricultural Science Bulletin 22(5):223-227.

Donald AW (1994). Preparing for Drought: A Guidebook for Developing Countries. Pennsylvania: Diane Books Publishing Company 7-8.

Gao K, Zhu TX, Han GD (2013). Impact of enclosure duration on plant functional and species diversity in Inner Mongolian grassland. Acta Prataculturae Sinica 22(6): 39-45.

Gao JB, Jiao KW, Wu SH, Ma DY, Zhao DS, Yin YH, Dai EF (2017). Past and future influence of climate change on spatially heterogeneous vegetation activity in China. Earth’s Future 1-20.

Guo LH, Wu SH, Zhao DS, Yin YH, Leng GY, Zhang QY (2014). NDVI-Based Vegetation Change in Inner Mongolia from 1982 to 2006 and Its Relationship to Climate at the Biome Scale. Advances in Meteorology. Doi: http://dx.doi.org/10.1155/2014/692068

Holben, Brent (1986). Characteristics of maximum-value composite images from temporal AVHRR data. International Journal of Remote Sensing 7 (11): 1417-1434. doi:10.1080/01431168608948945.

Huang YZ, Wang NA, He TH, Cheng HY, Zhao LQ (2009). Process of historical desertification of Mu Us desert and relationship between nature and human beings. Scientia Geographica Sinica 29(2), 206-211.

Jiang XY, Sara AR, Todd DR, David ML, Williams AP, Craig DA, Allison LS, Cai DM, Nate GMD (2013). Projected future changes in vegetation in western North America in the 21st century. Journal of Climate 26, 3671-3687.

Kammann CI, Linsel S, Gößling JW, Koyro HW (2011). Influence of biochar on drought tolerance of Chenopodium quinoa Willd and on soil - plant relations. Plant and soil 345 (1-2) :195-210.

Leal Filho, W. (2015) Handbook of Climate Change Adaptation. Springer, Berlin. 
Li B, Yong SP, Zeng SD, Cui HT (1990). The Principle, method, and application of ecological regionalizationexplanation of the ecological regionalization map of the Inner Mongolia autonomous region. Acta phytoecologica et geobotanica sinica 1(14):55-62.

Li DQ, Liu HL, Da FL (2007). The influence of climate drought on grassland animal husbandry. Animal husbandry and feed science 28(6):90. DOI: 10.3969/j.issn.1672-5190.2007.06.050

Li J, Wang YQ, Qu ZY, Ma LZ (2010). Characteristics of Temporal and Spatial Distribution of Drought Occurrence in Inner Mongolia Autonomous Region. Agricultural research in the arid areas 28(5): 266-272.

Li XH, Chen SH (2012). Assessment method of grassland loss from drought damage in Inner Mongolia. Pratacultural Science 29(7):1033-1038.

Liu GX, Zhuo Y, Yu FM, Jiang CL (2012). Study on Effect of Drought Based on Time Series on Grassland Vegetation in Eastern Inner Mongolia. Advanced Materials Research 518-523:5306-5315.

Liu HY, Cui HT, Pott R, Speier M (2010). Vegetation of the woodland-steppe transition at the southeastern edge of the inner Mongolian plateau. Journal of Vegetation Science 11 (4) :525-532.

Liu SL, Kang WP, Wang T (2016). Drought variability in Inner Mongolia of northern China during 19602013 based on standardized precipitation evapotranspiration index. Environmental Earth Sciences 75:145.

Liberato MLR, Ramos AM, Gouveia CM, Sousa P, Russo A, Trigo RM, Santo FE (2017). Exceptionally extreme drought in Madeira Archipelago in 2012: Vegetation impacts and driving conditions. Agricultural and Forest Meteorology 232: 195-209.

Marousek J, Vochozka M, Plachy J, Zakl J (2017). Glory and misery of biochar. Clean Technologies and Environmental Policy 19 (2) :311-317.

McKee TB, Doesken NJ, Kleist (1993). The relationship of drought frequency and duration to time-scales. Proceedings of the 8th Conference on Applied Climatology. Boston. Ma: American Meteorological Society 17(22): 179-183.

Mu SJ, Yang HF, Li JL, Chen YZ, Gang CC, Zhou W, Ju WM (2013). Spatio-temporal dynamic of vegetation coverage and its relationship with climate factors in Inner Mongolia, China. Journal of Geographical Sciences 23(2):231-246.

Mulcahy DN, Mulcahy DL, Dietz D (2013). Biochar soil amendment increases tomato seedling resistance to drought in sandy soils. Journal of Arid Environments 88 (1) :222-225.

Natsgadorj L (2003). Climate change. In: Batima, P. (Ed.), Climate Change: Pasture and Animal Husbandry. Institute of Meteorology and Hydrology of Mongolia, Ulaanbaatar 13-44.

Philip AF, Dawn MK, Jesse BN, Jonathan DC, Christopher WH (2008). Changes in grassland ecosystem function due to extreme rainfall events: implications for responses to climate change. Global Change Biology 14:1600-1608. Doi: 10.1111/j.1365-2486.2008. 01605.x 
Sarah JB, Chris BJ (2015). Extreme climate change and wet grasslands: plant traits for ecological resilience. Hydrobiologia 750:229-243. DOI:10.1007/s10750-014-2129-5

Spinoni J, Naumann G, Vogt JV, Barbosa P (2015). The biggest drought events in Europe from 1950 to 2012. Journal of Hydrology: regional studies 3, 509-524.

Tucker CJ, Pinzon JE, Brown ME, Slayback DA, Pak EW, Mahoney R, Vermote E, Saleous NE (2006). An extended AVHRR 8-km NDVDI dataset compatible with MODIS and SPOT vegetation NDVI data. International Journal of Remote Sensing 26(20), 4485-4498.

Vicente-Serrano SM, Beguería S, López-Moreno JI (2010). A multiscalar drought index sensitive to global warming: the standardized precipitation evapotranspiration index. Journal of Climate 23, 1696-1718.

Vicente-Serrano SM, Gouveiab C, Camarero JJ, Beguería S, Trigo R, López-Moreno JI, Azorín-Molina C, Pasho E, Lorenzo-Lacruz J, Revuelto J, Morán-Tejeda E, Sanchez-Lorenzo A (2013). Response of vegetation to drought time-scales across global land biomes. Proceedings of the National Academy of Sciences of the United States of America 110 (1), 52-57.

Wang, S. W., Lee, W-K., Son, Y. (2017) An assessment of climate change impacts and adaptation in South Asian Agriculture. International Journal of Climate Change Strategies and Management, 9 (4), 517-534.

Wang XL (2008). Accounting for autocorrelation in detecting mean-shifts in climate data series using the penalized maximal t or F test. Journal of applied meteorology and climatology 47(9):2423-2444.

Wang ZY, Xu DY, Yang H, Ding X, Li DJ (2017). Impacts of climate change and human activities on vegetation dynamics in Inner Mongolia, 1981-2010. Progress in Geography 36(8): 1025-1032. Doi: 10.18306/dlkxjz.2017.08.011

Wu LJ, Liu Q, Li L, Zhao X, Zhao TZ (2009). A review on the progress of the project of returning farmland to forest in China. Forestry Economics 21-37.

Xu G, Zhang H, Chen B, Zhang H, Innes JL, Wang G, Yan J, Zheng Y, Zhu Z, Myneni RB (2014). Changes in vegetation growth dynamics and relations with climate over China's land mass from 1982-2011. Remote Sensing 6,3263-3283. Doi:10.3390/rs6043263.

Yin J, Yin ZE, Xu SY (2013). Composite risk assessment of typhoon-induced disaster for China's coastal area. Natural Hazards 69:1423-1434.

Yuan XC, Zhou YL, Jin JL, Wei YM (2013). Risk analysis for drought hazard in China: a case study in Huaibei Plain, Natural hazards, 67:879-900. DOI: 10.1007/s11069-013-0614-1.

Yu M, Li Q, Hayes MJ, Svoboda MD, Heim RR (2014). Are droughts becoming more frequent or severe in China based on the standardized precipitation evapotranspiration index: 1951-2010? International Journal of climatology 34 (3), 545-558.

Zhang J, Li TL, Xu J (2005). Effect of sub-high temperature on photosythesis and carbon accumulation and distribution of Tomato in Green House. China Vegetables 3:7-10. 
Zhang JQ, Li N (2007). Quantitative methods and application of risk assessment and management on main meteorological disasters. Beijing Normal University.

Zhang QY, Wu SH, Zhao DS, Dai EF (2013). Responses of growing season vegetation changes to climate factors in Inner Mongolia Grassland. Journal of natural resources 28(5): 754-764.

Zhang Q, Kong DD, Singh VP, Shi PJ (2017). Response of vegetation to different time-scales drought across China: Spatiotemporal patterns, causes and implications. Global and Planetary Change,152:1-11.

Zhao XL, Li WL, Guo XL, Yu C, Zhao YT, Xu J (2017). The responses of Pa, SPI, and SPEI to dry climate in alpine meadows of eastern Qinghai-Tibet Plateau. Pratacultural Science 34(2):273-282. Doi: 10.11829/j.issn.1001-0629.2016-0187. 